\title{
Equine mesenchymal stromal cells and embryo-derived stem cells are immune privileged in vitro
}

\author{
Yasmin Z Paterson, Nicola Rash, Elaine R Garvican, Romain Paillot and Deborah J Guest ${ }^{*}$
}

\begin{abstract}
Introduction: Autologous mesenchymal stem cells (MSCs) are an attractive concept in regenerative medicine, but their mechanism of action remains poorly defined. No immune response is reported after in vivo injection of allogeneic equine MSCs or embryo-derived stem cells (ESCs) into the equine tendon, which may be due to the cells' immune-privileged properties. This study further investigates these properties to determine their potential for clinical application in other tissues.
\end{abstract}

Methods: Mitomycin C-treated MSCs, ESCs, or differentiated ESCs (dESCs) were cultured with allogeneic equine peripheral blood mononuclear cells (PBMCs), and their effect on PBMC proliferation, in the presence or absence of interferon-gamma (IFN- $\gamma$ ) was determined. MSCs and super-antigen (sAg)-stimulated PBMCs were co-cultured directly or indirectly in transwells, and PBMC proliferation examined. Media from MSC culture were harvested and used for PBMC culture; subsequent PBMC proliferation and gene expression were evaluated and media assayed for IFN-Y, tumor necrosis factor alpha (TNF-a), and interleukin (IL)-10 and IL-6 proteins with enzyme-linked immunosorbent assay (ELISA).

Results: Co-culture of PBMCs with ESCs or dESCs did not affect baseline proliferation, whereas co-culture with MSCs significantly suppressed baseline proliferation. Stimulation of PBMC proliferation by using super-antigens (sAgs) was also suppressed by co-culture with MSCs. Inhibition was greatest with direct contact, but significant inhibition was produced in transwell culture and by using MSC-conditioned media, suggesting that soluble factors play a role in MSC-mediated immune suppression. The MSCs constitutively secrete IL-6, even in the absence of co-culture with PBMCs. MSC-conditioned media also brought about a change in the cytokine-expression profile of sAg-stimulated PBMCs, significantly reducing PBMC expression of IL-6, IFN- $\gamma$, and TNF-a.

Conclusions: Equine MSCs and ESCs possess a degree of innate immune privilege, and MSCs secrete soluble factors that suppress PBMC proliferation and alter cytokine expression. These properties may make possible the future clinical use of allogeneic stem cells to help standardize and broaden the scope of treatment of tissue injuries.

\section{Introduction}

The use of autologous mesenchymal stromal/stem cells (MSCs) in clinical practice to aid tendon regeneration in horses [1] has gained popularity and acceptance in the last decade. Results from the clinical and experimental use of MSCs in regenerative medicine [2-5] have been promising, but details of the cellular mechanism of action remain unknown. Previous work has shown that

\section{*Correspondence: debbie.guest@aht.org.uk}

Animal Health Trust, Lanwades Park, Kentford, Newmarket, Suffolk CB8 7UU, UK

\section{Biomed Central}

MSC survival after injection into the injured tendon is low (39\% retention 6 hours after intra-arterial regional limb perfusion, $28 \%$ retention after intravenous administration [6,7], and $<5 \%$ survival 10 days after implantation [8]), which suggests that their beneficial effects are not brought about solely through their direct differentiation into tendon cells.

This theory is supported by the results of other studies using MSCs, which have shown them to function through trophic effects on endogenous cells [9] rather than through directed differentiation. MSCs have also been 
shown to have immunomodulatory properties both in vivo [10] and in vitro [5,11], and these attributes may render them potential candidates for the treatment of inflammatory conditions.

MSCs are currently being used in human trials to reduce inflammation in a range of conditions such as spinal cord injury [12], knee osteoarthritis [13], and liver failure [14]. In horses, immunomodulatory properties may suggest that equine MSCs could have potential use in the future treatment of inflammatory conditions such as osteoarthritis [15] or inflammatory airway disease.

Current clinical practice uses autologous MSCs. However, this approach requires aspiration of bone marrow from every horse, an invasive technique with the risk of potential complications, such as pneumopericardium [16]. After aspiration, culture expansion of MSCs to obtain sufficient numbers for clinical use can take up to 4 weeks, precluding the treatment of acute injuries during the initial inflammatory peak. In addition, treatment of each individual by using MSCs obtained from that individual makes it impossible to standardize treatment fully. In the horse, embryo-derived stem cells (ESCs) $[17,18]$ are also being investigated for their potential to aid tendon regeneration $[8,19]$ by providing an allogeneic source of cells that could be standardized to provide an "off-the-shelf" treatment. Equine ESCs have a high survival in the injured horse tendon without inducing any apparent immune response [8]. Furthermore, they appear to undergo some degree of tenocyte differentiation, which has also been demonstrated in vitro in response to TGF- $\beta 3$ and $3 \mathrm{D}$ culture [20]. However, whether equine ESCs would be immune privileged after transplantation and differentiation into other tissues remains unknown.

Many of the limitations of current autologous treatment could be overcome by the use of allogeneic MSCs or ESCs. Work in other species has demonstrated that ESCs are immune privileged to some degree, although they may ultimately still be recognized and consequently rejected by the immune system [21-24]. Likewise, both human and equine MSCs possess some ability to modulate an immune response [25-29], although their precise mechanism of action is largely unknown. It was previously shown that allogeneic equine MSCs can be transplanted into the injured tendon (single dose) [8], injected intradermally (two doses, 3 to 4 weeks apart) [30] or intraarticularly (single dose) [31] without eliciting an apparent immune response. Additionally, no changes in cellular or humoral immunity parameters were reported after intravenous injection of allogeneic MSCs into six healthy horses [32]. Recent in vitro results showed that equine MSCs do not significantly alter the baseline proliferation of nonactivated $\mathrm{T}$ cells $[28,30]$, but that they can decrease the proliferation of stimulated $\mathrm{T}$ cells [28]. When in co-culture with stimulated $\mathrm{T}$ cells, the MSCs were found to produce increased amounts of prostaglandin and IL-6 and to decrease the production of TNF- $\alpha$ and IFN- $\gamma$ by the T cells. Secreted prostaglandin $E_{2}$ recently was shown to be involved in equine MSC-mediated T-cell suppression [29].

To determine whether equine ESCs have the potential to be used in the treatment of injuries to tissue other than tendon, where cell replacement may be beneficial, we determined whether they were immune privileged in vitro by performing co-cultures with equine peripheral blood mononuclear cells (PBMCs). We also determined whether equine MSCs had immune-modulatory properties and if this was dependent on direct cell-tocell contact. In addition, we examined the resulting cytokine-expression profile of PBMCs after culture in MSC-conditioned media.

\section{Methods}

All of the work described was performed with the approval of the Animal Health Trust Ethical Review Committee and, where live experimental animals were involved, under UK Home Office Licence.

\section{Stem cell culture}

Three lines of previously characterized ESCs $[17,18]$ were used in this study. ESCs were cultured on mitotically inactivated mouse embryonic fibroblasts at $37.5^{\circ} \mathrm{C}$, $5 \% \mathrm{CO}_{2}$, in ESC medium (DMEM/F12 containing 15\% fetal bovine serum, $2 \mathrm{~m} M$ L-glutamine, 1\% nonessential amino acids, $1 \mathrm{~m} M$ sodium pyruvate, $0.1 \mathrm{~m} M \quad$ 2mercaptoethanol (all from Invitrogen, Renfrewshire, UK), and 1,000 units/ml leukemia inhibitory factor (LIF) (Sigma, Dorset, UK)). ESCs were passaged mechanically every 5 to 7 days in the presence of Effectine (PAA Laboratories, Somerset, UK). To induce differentiation, ESCs were passaged into conditions without feeder cells in the absence of LIF.

MSCs were derived from bone marrow aspirates taken from live Thoroughbred geldings, as described previously [33] or from Welsh mountain ponies immediately after euthanasia for reasons unrelated to this study. All MSCs were characterized according to their expression of surface antigens and tri-lineage differentiation, as described previously [34]. Two $10.5-\mathrm{ml}$ aliquots of bone marrow were aspirated into heparin (Sigma). Bone marrow was centrifuged through histopaque (Sigma), and the buffy layer of mononuclear cells was collected and washed in culture medium (DMEM supplemented with $10 \%$ fetal calf serum, $2 \mathrm{mM} \mathrm{L}$-glutamine, $100 \mathrm{U} / \mathrm{ml}$ penicillin, and $100 \mu \mathrm{g} / \mathrm{ml}$ streptomycin (all from Invitrogen, Paisley, UK)) before plating all recovered cells in $10 \mathrm{ml}$ medium onto a $10-\mathrm{cm}$ plate for incubation at $37.5^{\circ} \mathrm{C}, 5 \%$ $\mathrm{CO}_{2}$. Medium was replaced every 2 to 3 days to remove 
nonadherent cells, and adherent cells were passaged with $0.25 \%$ trypsin-EDTA (Sigma) every 3 to 7 days and replated at a seeding density of approximately $10,000 \mathrm{cells} / \mathrm{cm}^{2}$. Cells at passages 2 to 4 were frozen in liquid nitrogen until needed for culture.

Equine MSCs and ESCs were plated in standard growth media and allowed to attach overnight before the addition of $100 \mathrm{ng} / \mathrm{ml}$ equine IFN- $\gamma$ (R\&D Systems, Abingdon, UK) for $72 \mathrm{~h}$.

\section{Peripheral blood mononuclear cell isolation, culture, and stimulation with mitogen or Streptococcus equi superantigens}

Peripheral blood mononuclear cells (PBMCs) were purified by centrifugation on Ficoll-Hypaque (Amersham Biosciences, Uppsala, Sweden), as previously described [35]. Blood was collected from Welsh mountain ponies (not the same ponies from which MSCs were obtained) for reasons unrelated to this study, and only excess PBMCs were used for the following experiments. Pellets of excess PBMCs were resuspended in $1 \mathrm{ml}$ of PBMC media (RPMI-1630 (Sigma) with 10\% heat-inactivated fetal calf serum, $100 \mathrm{U} / \mathrm{ml}$ penicillin, and $100 \mu \mathrm{g} / \mathrm{ml}$ streptomycin, $2 \mathrm{~m} M$ L-glutamine, and $55 \mu M 2 \beta$-mercaptoethanol (as before)) and numerated.

For culture-stimulation experiments, PBMCs were treated with phytohemagglutinin (PHA) (Sigma) at a concentration of $5 \mu \mathrm{g} / \mathrm{ml}$ or Streptococcus equi superantigens (sAgs) (SeeM, SeeL, SeeI, and $\mathrm{SeeH}$, each at a final concentration of $0.125 \mu \mathrm{g} / \mathrm{ml}$ (AHT Bacteriology Unit)), as previously described [36].

\section{Mixed lymphocyte reactions and co-cultures}

For MLRs, mitomycin C (MMC)-treated MSCs and differentiated ESCs $(125 \mu \mathrm{g} / \mathrm{ml} \mathrm{MMC} \mathrm{for} \mathrm{2-hour} \mathrm{incuba-}$ tion) were cultured in 96-well plates in the presence of nonstimulated effector PBMCs at a ratio of 1:2 stem cells/PBMCs. For the negative control, MMC-treated PBMCs $(50 \mu \mathrm{g} / \mathrm{ml}$ MMC for 30 minutes) were washed and cultured with homologous effector PBMCs. For the positive control, MMC-treated PBMCs were cultured with heterologous effector PBMCs, both at ratios of 1:2 stimulator/effector PBMCs. After 5 days, PBMCs were treated with radioactive thymidine $\left({ }^{3} \mathrm{H}\right.$ thymidine) (GE Healthcare Bio-sciences) at a final concentration of $0.5 \mu \mathrm{Ci}$ per well and incubated at $37^{\circ} \mathrm{C}, 5 \% \mathrm{CO}_{2}$ for 16 to 18 hours. Cells were harvested and numerated. Three replicates using three lines of cells were performed.

For the ESCs co-cultures were also performed in sixwell plates because undifferentiated ESCs grow in colonies and require monolayer culture on a feeder layer to maintain their undifferentiated state. Therefore MMC-treated undifferentiated ESCs and differentiated ESCs were cultured with nonstimulated effector PBMCs at various ratios ranging from 1:25 to 1:100 in six-well plates. After 5 days, the proliferation of the PBMCs was determined by using ${ }^{3} \mathrm{H}$-thymidine incorporation. Six replicates with three lines of ESCs were performed.

To determine the immune modulatory properties of MSCs, MMC-treated MSCs were co-cultured with allogeneic PHA or sAg-stimulated PBMCs in six-well plates at ratios of 1:10 to 1:400. After 3 days, PBMC numbers were determined by using ${ }^{3} \mathrm{H}$-thymidine incorporation, and a percentage inhibition value for proliferation was calculated by using the formula: 100-((condition-NAx100)/(sAg-NA)) (where NA is nonactivated PBMCs, and sAg is sAgstimulated PBMCs). Three replicates using MSCs isolated from three different horses were performed.

\section{Transwell cultures}

Six-well plate transwell cultures with a $0.4 \mu M$ membrane pore size (Corning, Costar, Cambridge, MA, USA) were used to separate the MSCs physically from the sAg-stimulated PBMCs. PBMCs at a concentration of $10 \times 10^{6}$ cells $/ \mathrm{ml}$ were stimulated with $\mathrm{sAg}$, as previously described, and co-cultured with $1 \times 10^{5}$ MMC-treated MSCs, with the PBMCs in the inner chamber of the well and the adherent MSCs in the outer chamber. After 3 days, the PBMCs were quantified by using ${ }^{3} \mathrm{H}$-thymidine incorporation. Three replicates with MSCs isolated from three different horses were performed.

\section{MSC-conditioned media}

MSCs were cultured on $10-\mathrm{cm}$ plates until $70 \%$ to $80 \%$ confluent. Media were removed and replaced with PBMC medium, which was then harvested after 24, 48, and 72 hours. This supernatant, termed "MSC-conditioned medium," was then filtered through a $0.22-\mu \mathrm{m}$ filter (Nalgene, UK) and maintained at $4^{\circ} \mathrm{C}$ before use. sAgstimulated PBMCs and nonactivated PBMCs were incubated for 3 days with conditioned media from each time point. After incubation, the PBMCs were either quantified by using ${ }^{3}$ Hthymidine incorporation or centrifuged to pellet the cells, after which the supernatant was maintained at $-20^{\circ} \mathrm{C}$ until use in ELISAs, and PBMCs were resuspended in $1 \mathrm{ml}$ TRIzol (Ambion, Paisley, UK). Three replicates using MSCs isolated from three different horses were performed.

\section{Immunohistochemistry}

MSCs or ESCs were cultured on gelatin-coated (Sigma, Dorset, UK) coverslips with or without the addition of $100 \mathrm{ng} / \mathrm{ml}$ equine IFN- $\gamma$ ( $\mathrm{R}+\mathrm{D}$ Systems, Abington, UK) for 72 hours, fixed in 3\% paraformaldehyde (in PBS) for 20 minutes at room temperature, and permeabilized for 1 hour with $0.1 \%$ Triton-X-100 at room temperature. Primary antibody incubations with mouse anti-MHCI 1:200 and mouse anti-MHCII 1:200 (both VMRD, 
Pullman, WA, USA) were carried out overnight at $4^{\circ} \mathrm{C}$ before detection with a secondary antibody goat anti-mouse FITC 1:200 (Abcam, Cambridgeshire, UK). Three replicates for each cell type were performed by using cells isolated from different animals.

\section{Quantitative reverse transcription PCR}

PBMC total RNA was extracted by using TRIzol reagent followed by RNA isolation with RNeasy minicolumns and reagents (Qiagen Ltd., Crawley, Surrey, UK). Residual DNA was removed by performing an on-column DNAse digestion by using an RNase-free DNAse kit (Qiagen Ltd.), after which cDNA was synthesized by using the Superscript First-Strand Synthesis System for RT-PCR (Invitrogen). One-microliter aliquots of cDNA diluted 1:1,000 were amplified by polymerase chain reaction on a Quantica qPCR instrument (Techne), by using genespecific primers (Table 1 ) in a $25-\mu$ l reaction volume with a SYBR Green Core Kit for detection (Eurogentec, Seraing, Belgium). Relative expression levels were normalized with the housekeeping gene $18 \mathrm{~S}$ and calculated with the $2^{-\triangle \Delta C T}$ method [37]. Three replicates using conditioned media from MSCs isolated from three different horses were performed.

\section{ELISA assay}

The IL-6, IL-10, IFN- $\gamma$, and TNF- $\alpha$ concentrations in MSC-conditioned media were measured both before and after PBMC culture, by using species-specific competitive inhibition ELISAs (BlueGene, Shanghai, China, and R\&D Systems, Abingdon, UK) measured in duplicate on a microplate absorbance reader (ThermoMax Technologies, Columbia, MD, USA). Three replicates with conditioned media from MSCs isolated from three different horses were performed.

\section{Statistical analysis}

Data were analyzed by using one-way ANOVA with post hoc Tukey where appropriate (SPSS, IBM). Paired data were compared by using a Student $t$ test. A $P$ value of $<0.05$ was considered significant.

\section{Results}

Equine ESCs do not induce the proliferation of equine PBMCs, even after differentiation and pretreatment with IFN- $\gamma$

IFN- $\gamma$ pretreatment of ESCs qualitatively increased the intensity of MHC I staining on both undifferentiated and differentiated cells. However, no induction of MHC II antigens was observed (Figure 1A). The proliferative response of equine PBMCs was measured after co-culture with either undifferentiated ESCs or ESCs that had undergone spontaneous differentiation for 7 days. No increase in PBMC proliferation was observed, even after differentiation (Figure 1B). MHC I upregulation by IFN- $\gamma$ did not cause ESCs (either undifferentiated or differentiated) to produce a proliferative response from allogeneic PBMCs (Figure 1B).

Equine bone marrow-derived MSCs suppress background proliferation of unstimulated PBMCs even after pretreatment with IFN- $\gamma$

MSCs express MHC class I antigens, but no MHC class II antigens are detected by using immunocytochemistry. After exposure to IFN- $\gamma$, the intensity of MHC I staining is qualitatively increased, and MHC II expression is induced (Figure 2A and [34]). When directly co-cultured with bone marrow-derived MSCs, the baseline level of PBMC proliferation is significantly reduced to approximately $10 \%$ of the baseline (Figure $2 \mathrm{~B} ; P=0.00001$ ). This finding is in contrast to that observed with ESCs. Furthermore, after treatment with IFN- $\gamma$, MSCs continue to decrease significantly the baseline level of PBMC proliferation (Figure 2B; $P=0.000002$ ) to a level similar to that of nontreated MSCs with proliferation-inhibition values of $82.5 \%$ and $87.7 \%$, respectively.

\section{Equine bone marrow-derived MSCs suppress PBMCs activated with either PHA or sAgs}

Phytohemagglutinin (PHA) is commonly used to stimulate PBMC proliferation [39]. We previously demonstrated that streptococcal sAgs can also lead to PBMC proliferation [36]. By using either mitogen to stimulate PBMC proliferation, we found that co-culture with MSCs results in

Table 1 Primers used for RT-PCR [38]

\begin{tabular}{|c|c|c|}
\hline Primer & Forward $\left(5^{\prime}-3^{\prime}\right)$ & Reverse $\left(5^{\prime}-3^{\prime}\right)$ \\
\hline $18 \mathrm{~S}$ & ATGCGGCGGCGTTATTCC & GCTATCAATCTGTCAACTCCT \\
\hline TNF-a & AAAGGACATCATGAGCACTGAAAG & GGGCCCCCTGCCTTCT \\
\hline $\mathrm{IFN}-\gamma$ & CTACCTATTACTGCCAGGCCG & TCCAGGAAAAGAGGCCCAC \\
\hline IL-6 & TGCTGGCTAAGCTGCATTCA & GGAAATCCTCAAGGCTTCGAA \\
\hline$\| \mathrm{L}-8$ & TTGGCCGTCTTCCTGCTTT & GGTITGGAGTGCGTCTTGATG \\
\hline $\mid \mathrm{P}-10$ & CCTCCAGTTGCAGCACCAT & TTCCTTGAGTTCCACTCAGAGTCA \\
\hline CCL5 & CACTGCCACCTTCTGCACTC & CGGGAGATGTAGGCAAAGCA \\
\hline
\end{tabular}




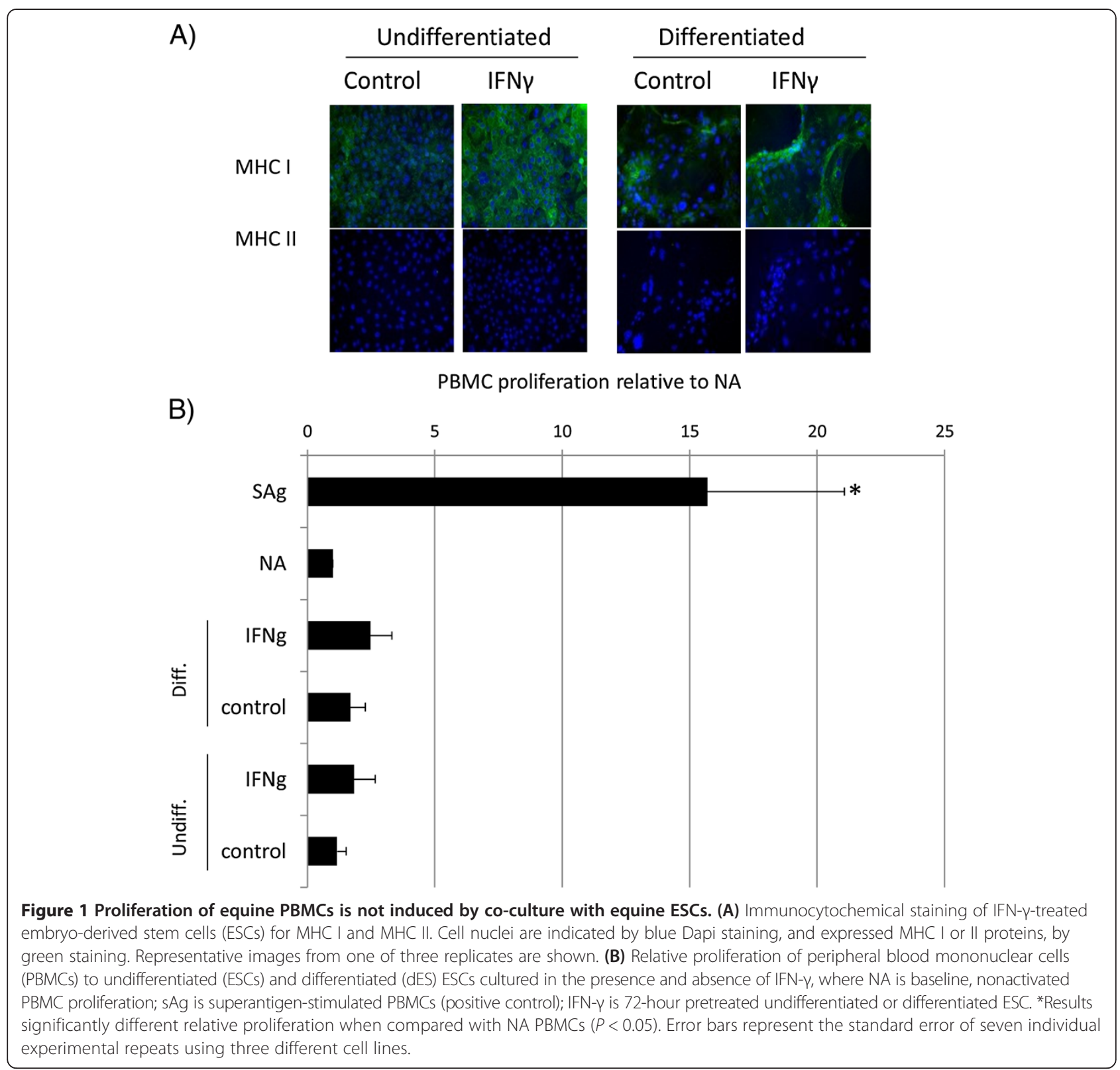

the inhibition of this proliferation (Figure 3). However, because the use of sAgs results in a greater, more consistent induction of PBMC proliferation, sAgs were used in all subsequent experiments.

MSCs suppress the proliferation of activated PBMCs to equivalent levels independent of the ratio

To determine whether the suppressive effects of the MSCs are lost with an increasing MSC-to-PBMC ratio, MSCs were co-cultured with sAg-activated PBMCs at ratios from 1:10 to 1:400. No significant differences were observed in the percentage inhibition within the tested ratio range, with inhibition remaining consistently high, at $79 \%$ to $93 \%$ (Figure $4 ; P=0.28$ ).
Equine bone marrow-derived MSCs secrete soluble factors that suppress activated PBMCs

In the absence of direct contact between the MSCs and PBMCs, proliferation of the activated PBMCs was inhibited to a significantly lesser degree than that observed when cells were in direct contact (94\% inhibition with direct contact; $55 \%$ inhibition in transwell system; $P=$ 0.006; Figure 5A).

Furthermore, conditioned media taken from cultures of actively proliferating MSCs cultured under standard conditions was used in the PBMC proliferation assays. Media that had been conditioned for 72 hours was found to bring about a $56 \%$ inhibition of proliferation, which was not significantly different from that seen in 


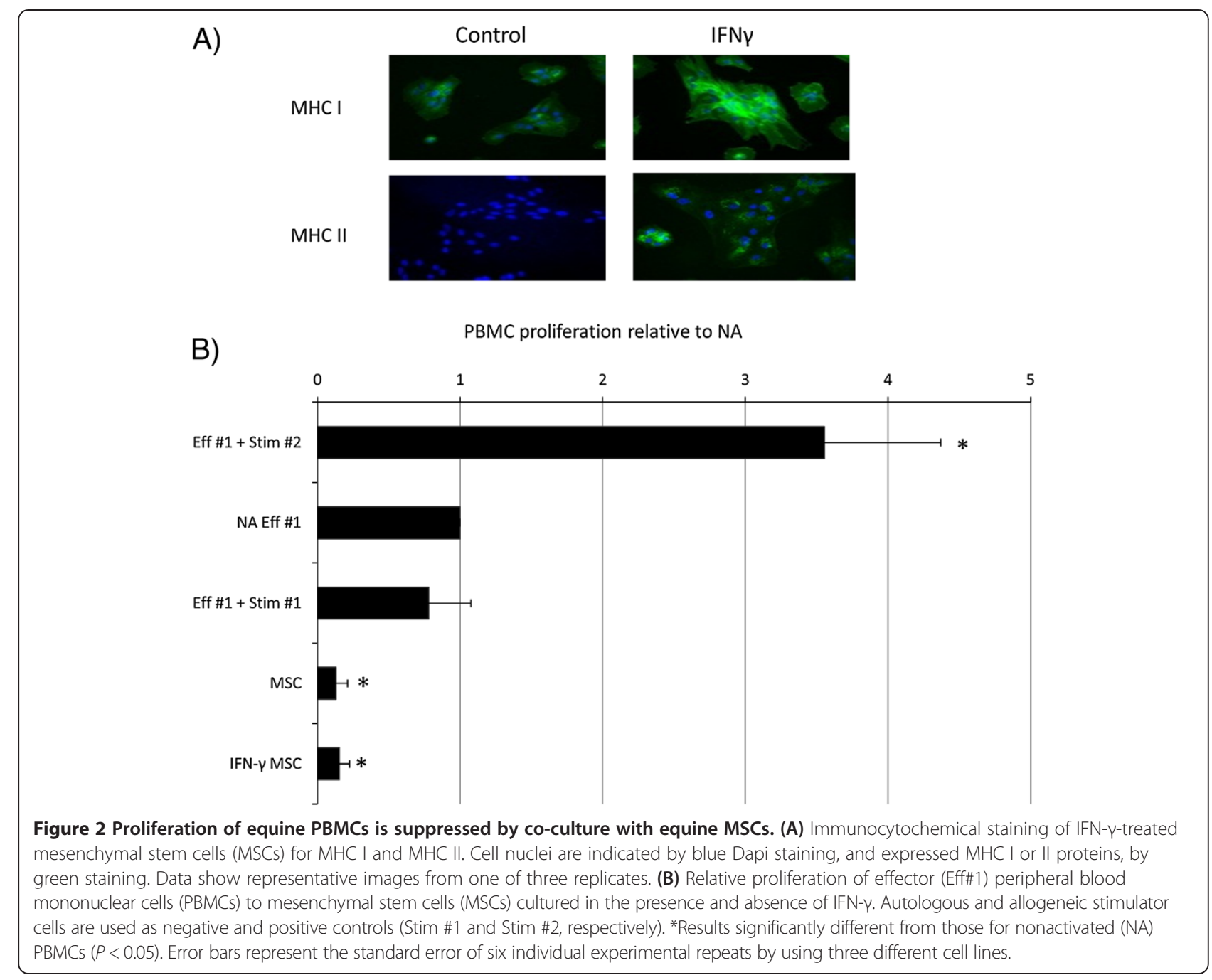

the presence of a transwell (Figure 5B). This demonstrates that the MSCs release soluble factors, even in the absence of any signals received from the PBMCs.

The factors released by equine MSCs also cause changes in the cytokine-expression profile and protein production of activated PBMCs

sAg-stimulation of PBMCs resulted in an increase in expression of IL-6, TNF- $\alpha$, and IFN- $\gamma$ mRNA (Figure 6). The presence of 24- to 72-hour MSC-conditioned media significantly reduced this upregulation in IL-6, and IFN- $\gamma$ mRNA ( $P<0.01$ for each time point). Addition of 48 - and 72-hour MSC-conditioned media reduced expression of IL-6 mRNA to a level not significantly different from that of unstimulated PBMCs. The observed reduction in expression of TNF- $\alpha$ mRNA did not reach significance for 24-, 48-, or 72-hour conditioned media $(P=0.09,0.08$, 0.07 , respectively). No significant changes in gene expression were observed for the chemokines IP-10, IL-8, and
CCL5 after activation of PBMCs by sAgs, and incubation with MSC-conditioned media had no additional effect (Figure 6).

MSC-conditioned media contained very low concentrations of the proteins IFN- $\gamma$, TNF- $\alpha$, and IL-10 (Figure 7). Media from nonstimulated PBMCs also contained very low concentrations. Production of IL-10 by PBMCs was significantly increased in response to both MSCconditioned media and sAg stimulation, when compared with nonstimulated PBMCs $(P<0.05)$. Concentrations of IFN- $\gamma$ and TNF- $\alpha$ in the media of sAg-stimulated PBMCs were significantly higher than those in nonstimulated PBMCs $(P<0.05)$. Culture in MSC-conditioned media significantly reduced this increase for IFN- $\gamma$, although concentrations remained significantly higher than those found in nonstimulated controls $(P<0.05)$. Culture in MSCconditioned media reduced TNF- $\alpha$ concentrations, although this reduction was significant for only 48-hour conditioned media $(P=0.04)$ and not for 72-hour conditioned media $(P=0.06)$ (Figure 7$)$. 


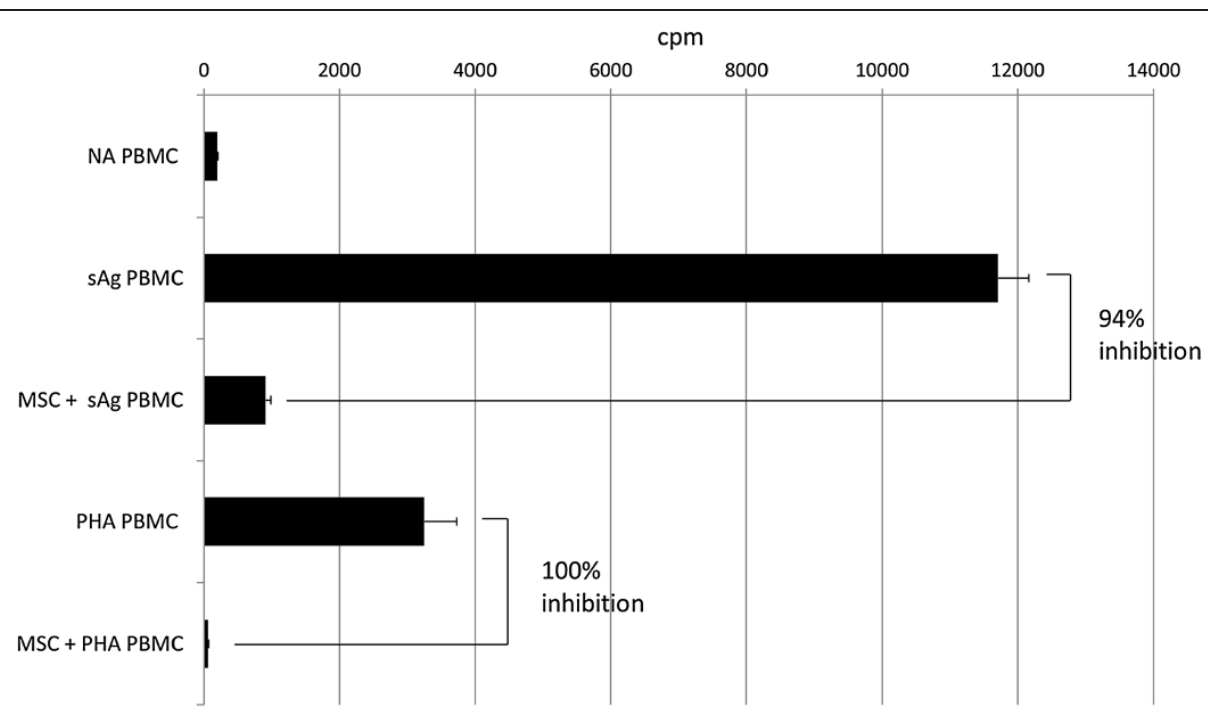

Figure 3 Proliferation of peripheral blood mononuclear cells (PBMCs) is increased with either S. equi super-antigens (sAg) or phytohemagglutinin (PHA) compared with nonactivated (NA) PBMCs and is inhibited by co-culture with allogeneic mesenchymal stem cells (MSCs). Graph depicts radioactive thymidine $\left({ }^{3} \mathrm{H}\right.$-thymidine) counts per minute (cpm) as a measure of cell proliferation. Error bars represent the standard deviation of triplicate wells of the same experiment, which is representative of the three replicates.

In contrast, MSC-conditioned media contained moderate concentrations of IL-6 protein, significantly more than nonstimulated PBMCs, in which expression was very low $(P<0.05)$. Stimulation of PBMCs with sAgs increased IL-6 production, but this failed to reach significance $(P=0.08)$. Culture of PBMCs in MSC-conditioned media resulted in concentrations of IL- 6 that were not significantly different from those measured in MSCconditioned media (Figure 7; $P<0.05$ ).

\section{Discussion}

When research into regenerative medicine was in its infancy, it was assumed that the observed clinical benefit of exogenous MSCs was due to in situ differentiation of the multipotent cells in a tissue-specific manner. This simplistic view is gradually being replaced with a more sophisticated understanding of the paracrine effect of such cells and their role secreting bioactive molecules and delivering soluble factors to the host cells. This

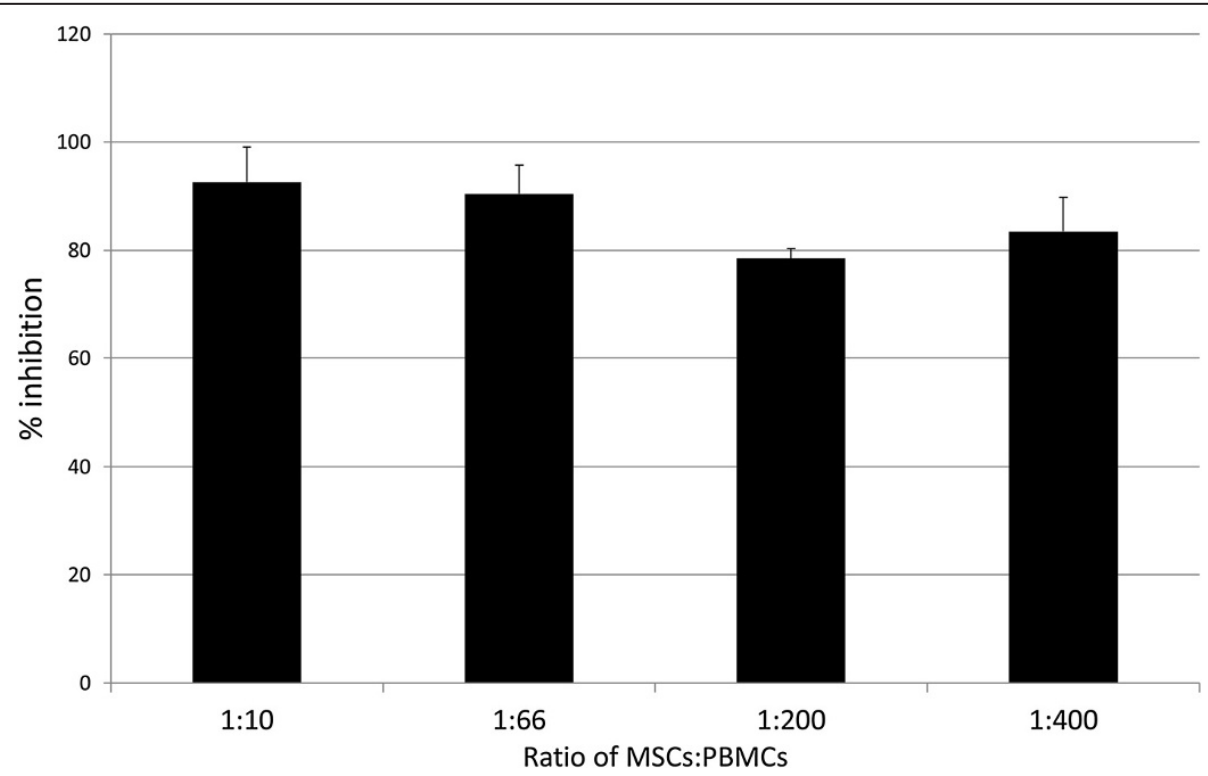

Figure 4 Percentage inhibition of S. equi superantigen (sAg)-induced peripheral blood mononuclear cells (PBMCs) proliferation when co-cultured with mesenchymal stem cells (MSCs) at ratios of 1:10, 1:66, 1:200, and 1:400 (MSC to PBMC). Error bars represent the standard error of the mean of three biologic repeats. No significant differences are observed between the ratios $(P>0.05)$. 


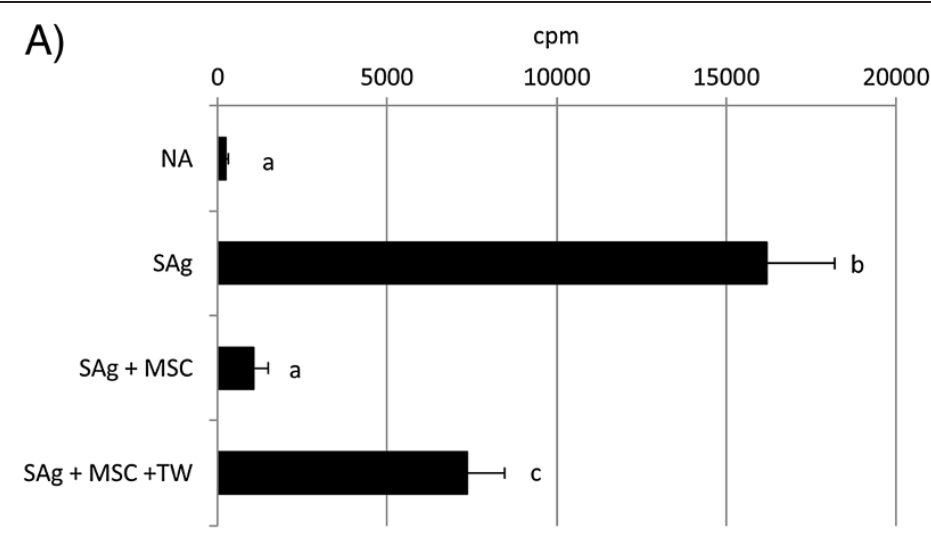

B)

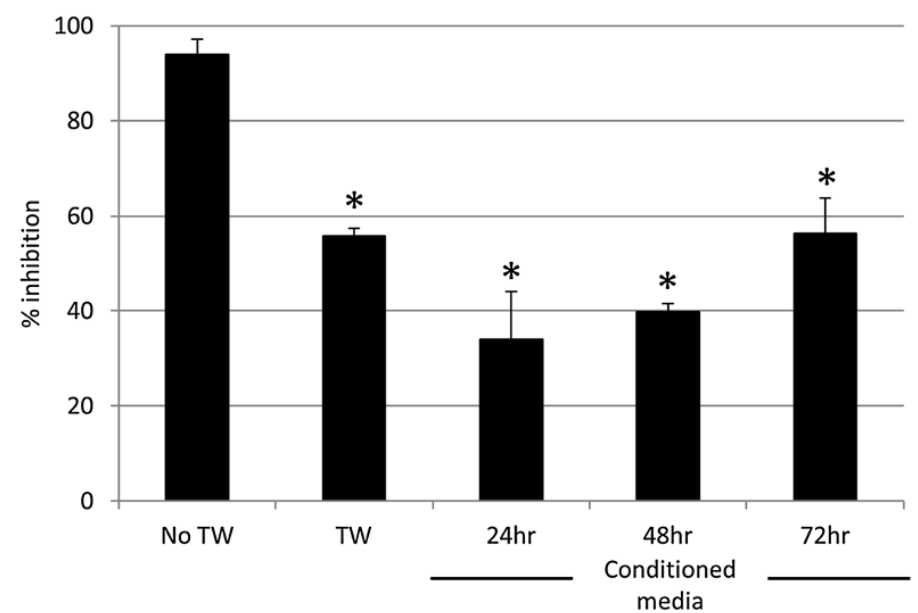

Figure 5 Soluble factors are involved in MSC-mediated PMBC suppression. (A) Mesenchymal stem cells (MSCs) suppress S. equi superantigen (sAg)-induced peripheral blood mononuclear cells (PBMCs) proliferation when separated by a transwell membrane (TW). Graph depicts radioactive thymidine ( ${ }^{3} \mathrm{H}$-thymidine) counts per minute $(\mathrm{cpm})$ as a measure of cell proliferation. Differing letter annotations denote a significantly different mean (ANOVA, all $P<0.05$ ). Error bars represent the standard error of the mean of three biologic repeats. (B) Exposure to 24-, 48-, and 72-hour mesenchymal stem cell (MSC)-conditioned media suppresses $S$. equi superantigen (SAg)-induced peripheral blood mononuclear cell (PBMC) proliferation, but to a lesser extent than via direct cell-to-cell contact. TW, transwell. * Results significantly different from no transwell (No TW) values (ANOVA; $P<0.05)$. Error bars represent the standard error of the mean of three biologic repeats.

study sheds further light on the immunosuppressive properties of MSCs and ESCs and contributes supporting evidence for the future clinical application of allogeneic cells as a regenerative therapy.

The International Society for Cellular Therapy (ISCT) defined human MSCs as being MHC I positive and MHC II negative [40], and previous reports confirmed that equine MSCs express MHC I [28,31,34,41,42]. MHC I expression has been reported in $62 \%$ to $99 \%$ of equine MSCs in these reports, with variability probably due to differences in cell source, passage, antibodies, and laboratory techniques. Multiple studies have shown that equine MSCs do not express MHC II [28,31,34,41]; however, a more recent article suggests that equine MSCs may express variable levels of MHC II, depending on the passage, horse, cell isolation repeat, or culture conditions [42]. Here we demonstrate that both equine
ESCs and MSCs, under our culture conditions, express MHC I but not MHC II.

In other species, it is well established that allogeneic MHC-mismatched MSCs do not elicit a proliferative response when cultured with allogeneic PBMCs in vitro, resulting instead in a significant reduction in proliferative action [43]. Similar results have recently been demonstrated in the horse [28] in a T-cell-selective population. However, contrary to our findings, background suppression of PBMC proliferation by MSCs was not reported there; we observed significant baseline suppression of PBMC proliferation in culture with MSCs, but not with ESCs. The observed $80 \%$ reduction in baseline proliferation is comparable to that observed in canine studies [44].

Our study further supports this concept of immune modulation, with MSCs implementing a reduction in alloreactive lymphocyte proliferation independent of cell 


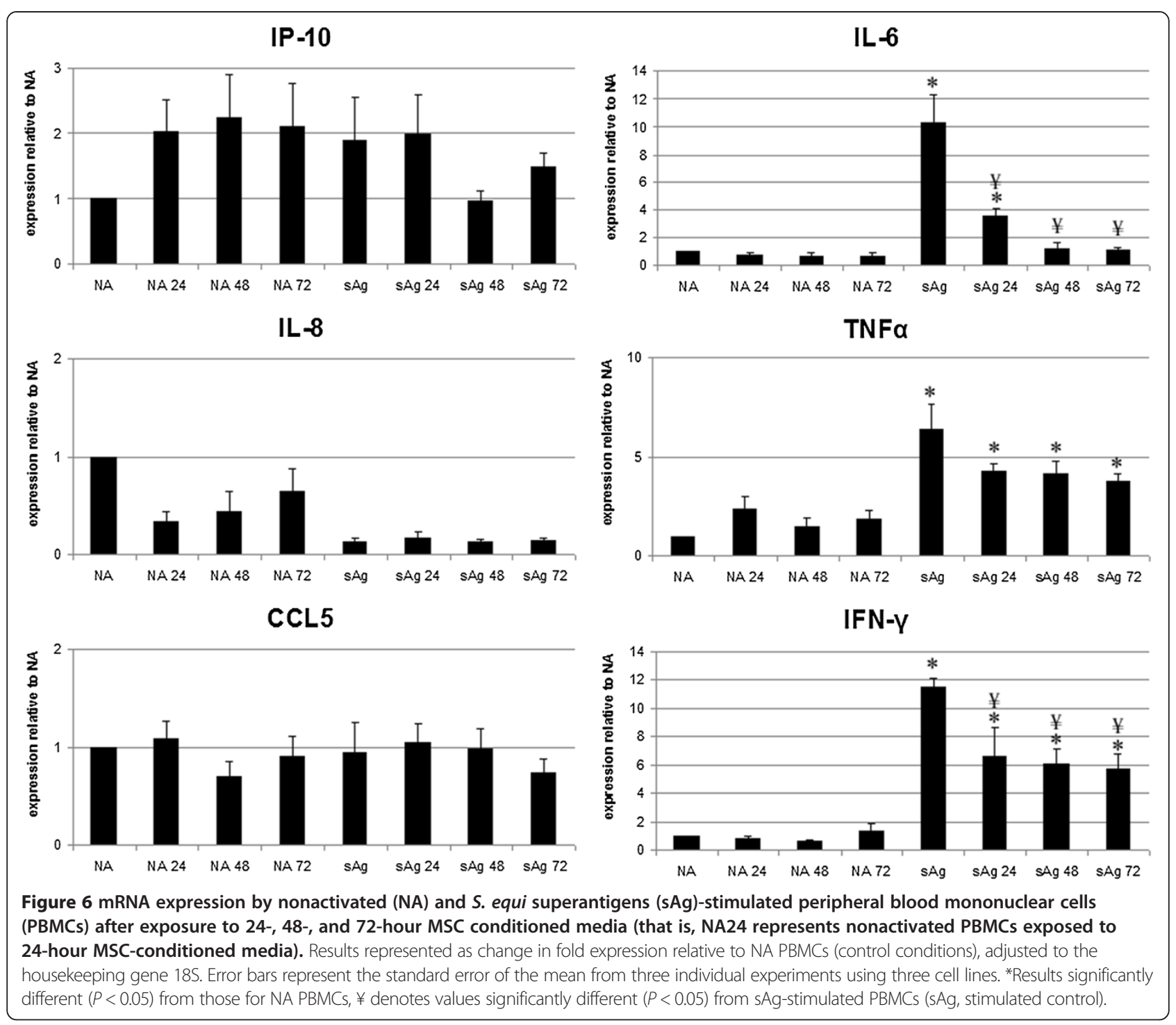

ratio (from 1:10 to 1:400 MSC/PBMC). Again, this is in contrast to a previous report in the horse [28] and may reflect differences in the immune cell population (T-cellselective versus nonenriched PBMC population) or differences in the actual numbers of MSCs used, which has been shown to affect their suppressive effects [45]. We further demonstrated, for the first time in the horse, that MSC-mediated suppression of PBMC proliferation also occurs when using indirect culture or MSC-conditioned media. This supports recent data that demonstrate the involvement of secreted prostaglandin $\mathrm{E}_{2}$ in MSC-mediated T-cell suppression [29].

Human adipose-derived multipotent stem cells (AdMSs) demonstrated similar immunomodulatory effects to BMSCs, with both sources suppressing proliferation of stimulated PBMCs and inhibiting monocyte-derived immature dendritic cell differentiation. However, the AdMS cells appeared more potent and secreted greater concentrations of IL- 6 and TGF- $\beta 1$, suggesting that the increased cytokine secretion may contribute to a greater immunomodulatory potency [46]. The proposal that cytokine secretion forms at least part of the mechanism of action is supported in our study by the demonstration that direct contact between cell types is not necessary for the observed inhibitory effect; indeed, simultaneous presence of both MSCs and PBMCs was shown to be not essential, as MSCs are able to suppress alloreactive lymphocytes in both indirect (transwell) and time-lapsed (preconditioning) culture.

Both mRNA and protein expression for the proinflammatory cytokines TNF- $\alpha$ and IFN- $\gamma$ by activated PBMCs was reduced by culture in MSC-conditioned media. This finding supports previously reported decreases in TNF- $\alpha$ and IFN- $\gamma$ mRNA expression in human, murine, and equine studies $[27,28,47,48]$, and supports the hypothesis that MSCs promote tissue healing via their ability to 


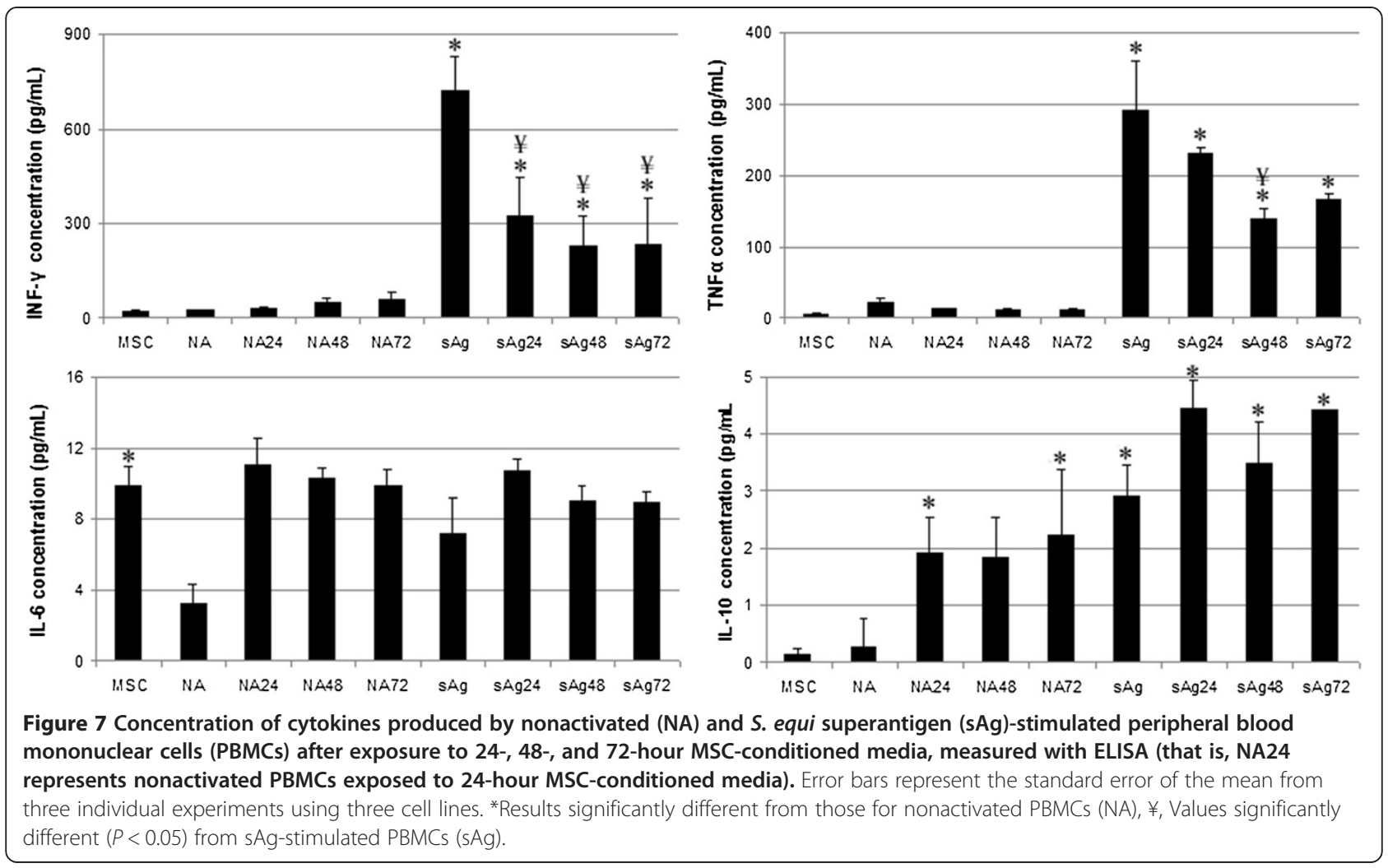

decrease immune cell inflammatory signals. Although expression of IL-6 mRNA was similarly decreased in the presence of MSC-conditioned media, the higher baseline production of IL- 6 by MSCs may have masked any corresponding downregulation in protein expression by PBMCs. Our finding that equine MSCs constitutively express IL-6 is in contrast to previous reports [28], although in agreement with findings from other species [49]. It has been suggested that IL-6 production by MSCs is a key component of their immune privilege and that postimplantation rejection of allogeneic MSCs may be related to a reduction in cellular IL- 6 concentrations [49], although inhibition of IL-6 did not affect equine MSC-mediated T-cell suppression in a recent study [29].

Our study found no increase in chemokine mRNA expression (IP-10, CCL5, IL-8) after sAg activation of PBMCs. In contrast, studies on human allogeneic MSCs and PBMCs demonstrated upregulation of chemokine expression and protein release after stimulation with inflammatory mediators [50]. It is also hypothesized that MSCs promote antiinflammatory signaling, by upregulating key antiinflammatory cytokines such as IL-10 $[27,28,30]$, as observed here.

We, and others previously demonstrated that MSCs upregulate $\mathrm{MHCI}$ expression and induce expression of MHCII in response to IFN- $\gamma[34,42]$. Although our study did not quantify the level of expression, this would be interesting to explore in future experiments, as our results suggest that although the majority of equine MSCs and ESCs express MHC I under normal conditions, the level of expression is increased after IFN- $\gamma$ treatment. In addition, IFN- $\gamma$ acts as a major regulator of the expression of chemokines and their receptors in human MSCs [50]. Although in human tendons, IFN- $\gamma$ levels remain below detection levels after injury [51], in the injured equine superficial digital flexor tendon, a significant percentage of tenocytes have been shown to be IFN- $\gamma$ immunopositive [52]. These data confirm that addition of IFN- $\gamma$ does not reduce the immune privilege of either ESCs or MSCs, although the resultant effect on MHC expression differed (significant upregulation of MHC I, with no effect on MHC II in ESC lines, in comparison with upregulation of both MHC I and II in MSCs).

It has been suggested that low MHC expression results in a reduction of stimulatory signals to aid in evasion of an immune attack [22,24], forming an additional or alternate mechanism by which MSCs and ESCs were able to avoid stimulation of a proliferative response in PBMCs. Similar findings are attributed to studies on human MSCs [45,53], but MHC II expression has been associated with MHC-mismatched T-cell proliferation in horses [42]. The haplotypes of the horses used in the current study are unknown, but these conflicting results warrant further research. An absence of co-stimulatory molecules in human 
MSCs may also help them to evade the immune system [54], and although some of these molecules are expressed at the mRNA level in equine MSCs [41], a lack of equinespecific antibodies has precluded detailed investigations to date.

Equine ESCs have been observed to undergo a degree of tenocyte differentiation after implantation into injured tendon in vivo and furthermore, not to elicit an immune response [19]. However, the relative importance of the host tendon tissue in this immune privilege is not known, as equine ESCs have not, to date, been implanted into other tissues. In this study, we demonstrated that equine ESCs do not induce the proliferation of allogeneic PBMCs, even after their spontaneous differentiation. This may in part be due to a lack of MHC II expression by both undifferentiated and differentiated ESCs, even after exposure to IFN- $\gamma$ and supports results reported in ESCs from other species [24]. When equine ESCs are allowed to undergo spontaneous differentiation, a mixed population of differentiated cell types is produced, which contains cells derived from all three germ layers $[17,18]$. The observed lack of induction of PBMC proliferation after in vitro differentiation therefore supports further in vivo research into their application in other tissues. Unlike, MSCs, equine ESCs did not suppress baseline PBMC proliferation, which may suggest that they do not have the same immunosuppressive properties as MSCs. However, the effect of ESCs on the proliferation of activated PBMCs was not performed in this study and should be addressed in the future.

Furthermore, the effect of repeated doses of stem cells for therapeutic aims is not known and should form part of future work. In baboons, multiple administrations of high doses of allogeneic MSCs reportedly affected alloreactive immune responses without compromising the overall immune system of recipient baboons [55]. The authors concluded that induction of host T-cell hyporesponsiveness to donor alloantigens may facilitate MSC survival. Additionally, equine umbilical cord blood stem cells neither stimulated, nor suppressed, baseline proliferation rates of PBMCs in vitro, or after repeated administration in vivo [30].

\section{Conclusion}

In conclusion, both MSCs and ESCs are attractive targets for the development of allogeneic cellular therapy. Equine ESCs did not affect baseline PBMC proliferation, even after differentiation and/or MHC upregulation by IFN- $\gamma$. In contrast, equine MSCs have a profound suppressive effect on allogeneic lymphocytes, a feature not dependent on MHC expression, suggesting efficacy regardless of donor MHC haplotype. Preservation of this suppressive effect on mitogen-stimulated PBMCs, along with the suppression of pro-inflammatory cytokine production, suggests that clinical delivery into an inflamed environment may also be valuable. MSCs have potential as immuneregulatory tools for the treatment of immune-mediated and inflammatory diseases, such as osteoarthritis and inflammatory airway disease, through their ability to produce immunomodulatory trophic factors.

\section{Abbreviations}

AdMS: Adipose-derived multipotent stem cell; CCL5: chemokine ligand 5; cpm: counts per minute; ELISA: enzyme linked immunosorbent assay; ESC: embryonic stem cell; IFN-ץ: interferon gamma; IL-10: interleukin 10; IP-10: interferon gamma-induced protein 10; MHC: major histocompatibility complex; MMC: mitomycin C; MSC: mesenchymal stem cell; NA: nonactivated; PBMC: peripheral blood mononuclear cell; PCR: polymerase chain reaction; sAg: S. equi superantigen; TGF- $\beta$ : transforming growth factor beta; TNF-a: tumor necrosis factor alpha.

\section{Competing interests}

The authors declare that they have no competing interests.

\section{Authors' contributions}

The study was conceived and designed by DG and RP. YP, NR, and EG performed the majority of the data acquisition and analysis. All authors contributed to data interpretation. Manuscript preparation was undertaken by EG, YP, and DG. NR and RP revised the manuscript. All authors read the final manuscript and gave approval for it to be published.

\section{Acknowledgements}

This study was in part funded by the Paul Mellon Foundation.

Received: 19 February 2014 Revised: 11 July 2014

Accepted: 14 July 2014 Published: 30 July 2014

\section{References}

1. Smith RK, Korda M, Blunn GW, Goodship AE: Isolation and implantation of autologous equine mesenchymal stem cells from bone marrow into the superficial digital flexor tendon as a potential novel treatment. Equine Vet J 2003, 35:99-102.

2. Ouyang HW, Goh JC, Thambyah A, Teoh SH, Lee EH: Knitted poly-lactide-co-glycolide scaffold loaded with bone marrow stromal cells in repair and regeneration of rabbit Achilles tendon. Tissue Eng 2003, 9:431-439.

3. Hankemeier S, Keus M, Zeichen J, Jagodzinski M, Barkhausen T, Bosch U, Krettek C, Van Griensven M: Modulation of proliferation and differentiation of human bone marrow stromal cells by fibroblast growth factor 2: potential implications for tissue engineering of tendons and ligaments. Tissue Eng 2005, 11:41-49.

4. Godwin EE, Young NJ, Dudhia J, Beamish IC, Smith RK: Implantation of bone marrow-derived mesenchymal stem cells demonstrates improved outcome in horses with overstrain injury of the superficial digital flexor tendon. Equine Vet J 2012, 44:25-32.

5. Lange-Consiglio A, Rossi D, Tassan S, Perego R, Cremonesi F, Parolini O: Conditioned medium from horse amniotic membrane-derived multipotent progenitor cells: immunomodulatory activity in vitro and first clinical application in tendon and ligament injuries in vivo. Stem Cells Dev 2013, 22:3015-3024.

6. Becerra P, Valdés MA, Fiske-Jackson AR, Dudhia J, Neves F, Hartman NG, Smith RKW: The distribution of injected technetium99m-labelled mesenchymal stem cells in horses with naturally occurring tendinopathy. J Orthop Res 2013, 31:1096-1102.

7. Sole A, Spriet M, Galuppo LD, Padgett KA, Borjesson DL, Wisner ER, Brosnan RJ, Vidal MA: Scintigraphic evaluation of intra-arterial and intravenous regional limb perfusion of allogeneic bone marrow-derived mesenchymal stem cells in the normal equine distal limb using 99mTc-HMPAO. Equine Vet J 2011, 44:594-599.

8. Guest DJ, Smith MR, Allen WR: Equine embryonic stem-like cells and mesenchymal stromal cells have different survival rates and migration patterns following their injection into damaged superficial digital flexor tendon. Equine Vet J 2010, 42:636-642. 
9. Li N, Sarojini H, An J, Wang E: Prosaposin in the secretome of marrow stroma-derived neural progenitor cells protects neural cells from apoptotic death. J Neurochem 2010, 112:1527-1538.

10. Koch M, Lehnhardt A, Hu X, Brunswig-Spickenheier B, Stolk M, Bröcker V, Noriega $M$, Seifert M, Lange C: Isogeneic MSC application in a rat model of acute renal allograft rejection modulates immune response but does not prolong allograft survival. Transpl Immunol 2013, 29:43-50.

11. Yoo KH, Jang IK, Lee MW, Kim HE, Yang MS, Eom Y, Lee JE, Kim YJ, Yang SK, Jung $\mathrm{HL}$, Sung KW, Kim CW, Koo HH: Comparison of immunomodulatory properties of mesenchymal stem cells derived from adult human tissues. 2009, 2:150-156

12. Forostyak $\mathrm{S}$, Jendelova $\mathrm{P}$, Sykova $\mathrm{E}$ : The role of mesenchymal stromal cells in spinal cord injury, regenerative medicine and possible clinical applications. Biochimie 2013, 95:2257-2270.

13. Orozco L, Munar A, Soler R, Alberca M, Soler F, Huguet M, Sentís J, Sánchez A, García-Sancho J: Treatment of knee osteoarthritis with autologous mesenchymal stem cells: a pilot study. Transplantation 2013, 95:1535-1541.

14. Shi M, Zhang Z, Xu R, Lin H, Fu J, Zou Z, Zhang A, Shi J, Chen L, Lv S, He W, Geng $H$, Jin L, Liu Z, Wang FS: Human mesenchymal stem cell transfusion is safe and improves liver function in acute-on-chronic liver failure patients. Stem Cells Transl Med 2012, 1:725-731.

15. Frisbie DD, Kisiday JD, Kawcak CE, Mcllwraith CW, Werpy NM: Evaluation of adipose derived stromal vascular fraction or bone marrow derived mesenchymal stem cells for treatment of osteoarthritis. J Orthop Res 2009, 27:1675-1680.

16. Durando MM, Zarucco L, Schaer TP, Ross M, Reef VB: Pneumopericardium in a horse secondary to sternal bone marrow aspiration. Equine Vet Educ 2006, 18:75-79.

17. Guest DJ, Allen WR: Expression of cell surface antigens and embryonic stem cell pluripotency genes in equine blastocysts. Stem Cells Dev 2007, 16:789-795.

18. Li X, Zhou SG, Imreh MP, Ahrlund-Richter L, Allen WR: Horse embryonic stem cell-like cell lines from the proliferation of inner cell mass cells. Stem Cells Dev 2006, 15:523-531.

19. Barsby TG, Guest DJ: Transforming growth factor Beta3 promotes tendon differentiation of equine embryo-derived stem cells. Tissue Eng Part $A$ 2013, 19:2156-2165.

20. Barsby TG, Bavin E, Guest D: 3-dimensional culture and transforming growth factor Beta3 synergistically promote tenogenic differentiation of equine embryo-derived stem cells. Tissue Eng Part A 2014. epub ahead of print.

21. Magliocca JF, Held IK, Odorico JS: Undifferentiated murine embryonic stem cells cannot induce portal tolerance but may possess immune privilege secondary to reduced major histocompatibility complex antigen expression. Stem Cells Dev 2006, 15:707-717.

22. Li L, Baroja ML, Majumdar A: Human embryonic stem cells possess immune-privileged properties. Stem Cells 2004, 22:448-456.

23. Menard C, Hagege AA, Agbulut O: Transplantation of cardiac committed mouse embryonic stem cells to infarcted sheep myocardium: a preclinical study. Lancet 2005, 366:1005-1012

24. Drukker M, Katchman H, Katz G: Human embryonic stem cells and their differentiated derivatives are less susceptible to immune rejection than adult cells. Stem Cells 2006, 24:221-229.

25. Maccario R, Podestà M, Moretta A, Cometa A, Comoli P, Montagna D, Daudt L, Ibatici A, Piaggio G, Pozzi S, Frassoni F, Locatelli F: Interaction of human mesenchymal stem cells with cells involved in alloantigen-specific immune response favors the differentiation of CD4+ T-cell subsets expressing a regulatory/suppressive phenotype. Haematologica 2005, 90:516-525.

26. Corcione A, Benvenuto F, Ferretti E, Giunti D, Cappiello V, Cazzanti F, Risso M, Gualandi F, Mancardi GL, Pistoia V, Uccelli A: Human mesenchymal stem cells modulate B-cell functions. Blood 2006, 107:367-372.

27. Aggarwal S, Pittenger MF: Human mesenchymal stem cells modulate allogeneic immune cell responses. Blood 2005, 105:1815-1822.

28. Carrade DD, Lame MW, Kent MS, Clark KC, Walker NJ, Borjesson DL: Comparative analysis of the immunomodulatory properties of equine adult-derived mesenchymal stem cells. Cell Med 2012, 4:1-11.

29. Carrade DD, Wood JA, Granick JL, Walker NJ, Clark KC, Borjesson DL: Equine mesenchymal stem cels inhibit T cell proliferation through different mechanisms depending on tissue source. Stem Cell Dev 2014. epub ahead of print.

30. Carrade DD, Affolter VK, Outerbridge CA, Watson JL, Galuppo LD, Buerchler S, Kumar V, Walker NJ, Borjesson DL: Intradermal injections of equine allogeneic umbilical cord-derived mesenchymal stem cells are well tolerated and do not elicit immediate or delayed hypersensitivity reactions. Cytotherapy 2011, 13:1180-1192.

31. Carrade DD, Owens SD, Galuppo LD, Vidal MA, Ferraro GL, Librach F, Buerchler S, Friedman MS, Walker NJ, Borjesson DL: Clinicopathologic findings following intra-articular injection of autologous and allogeneic placentally derived equine mesenchymal stem cells in horses. Cytotherapy 2011, 13:419-430.

32. Broeckx S, Forier R, Marien T, Suis M, Savkovic V, Franco-Obregon A, Duchateau $L$, Spaas $J H$ : The influence of allogenic mesenchymal stem cells on the haematological status of horses. J Stem Cell Res Ther 2013, 3:136.

33. Guest DJ, Smith MR, Allen WR: Monitoring the fate of autologous and allogeneic mesenchymal progenitor cells injected into the superficial digital flexor tendon of horses: preliminary study. Equine Vet J 2008, 40:178-181

34. Guest DJ, Ousey JC, Smith MRW: Defining the expression of marker genes in equine mesenchymal stromal cells. Stem Cells Cloning Adv Appl 2008, $1: 1-9$.

35. Paillot R, Prowse L, Montesso F, Huang CM, Barnes H, Escala J: Whole inactivated equine influenza vaccine: efficacy against a representative clade 2 equine influenza virus, IFNgamma synthesis and duration of humoral immunity. Vet Microbiol 2013, 162:396-407.

36. Paillot R, Robinson C, Steward K, Wright N, Jourdan T, Butcher N, Heather Z, Waller AS: Contribution of each of four superantigens to Streptococcus equi-induced mitogenicity, IFN gamma synthesis and immunity. Infect Immun 2010, 78:1728-1739.

37. Livak KJ, Schmittgen TD: Analysis of relative gene expression data using real-time quantitative PCR and the 2-[Delta][Delta]CT method. Methods 2001, 25:402-408.

38. Figueiredo MD, Salter CE, Andrietti ALP, Vandenplas ML, Hurley DJ, Moore JN: Validation of a reliable set of primer pairs for measuring gene expression by real-time quantitative RT-PCR in equine leukocytes. Vet Immun Immunopathol 2009, 131:65-72.

39. Clara M, Ausiello GC, Spagnoli MB, Boccanera M, Casalinuovo I, Malavasij F, Casciani CU, Cassone A: Proliferation of human peripheral blood mononuclear cells induced by Candida albicans and its cell wall fractions. Med Microbiol 1986, 22:195-202.

40. Dominici M, Le Blanc K, Mueller I, Slaper-Cortenbach I, Marini FC, Krause DS, Deans RJ, Keating A, Prockop DJ, Horwitz EM: Minimal criteria for defining multipotent mesenchymal stromal cells. Int Soc Cell Therapy Position Statement Cytother 2006, 8:315-317.

41. De Schauwer C, Goossens K, Piepers S, Hoogewijs M, Govaere J, Smits K, Van Soom A, van de Walle GR: Characterization and profiling of immunomodulatory genes of equine mesenchymal stromal cells from non-invasive sources. Stem Cell Res Ther 2014, 5:6-10.

42. Schnabel LV, Pezzanite LM, Antczak DF, Felippe MJ, Fortier LA: Equine bone marrow-derived mesenchymal stromal cells are heterogeneous in $\mathrm{MHC}$ class II expression and capable of inciting an immune response in vitro. Stem Cell Res Ther 2014, 5:13.

43. Bartholomew A, Sturgeon C, Siatskas M, Ferrer K, Mclntosh K, Patil S, Hardy W, Devine S, Ucker D, Deans R, Moseley A, Hoffman R: Mesenchymal stem cells suppress lymphocyte proliferation in vitro and prolong skin graft survival in vivo. Exp Hematol 2002, 30:42-48.

44. Lee WS, Suzuki Y, Graves SS, Iwata M, Venkataraman GM, Mielcarek M, Peterson LJ, Ikehara S, Torok-Storb B, Storb R: Canine bone marrow-derived mesenchymal stromal cells suppress alloreactive lymphocyte proliferation in vitro but fail to enhance engraftment in canine bone marrow transplantation. Biol Blood Marrow Transplant 2011, 17:465-475.

45. Le Blanc K, Tammik L, Sundberg B, Haynesworth SE, Ringdén O: Mesenchymal stem cells inhibit and stimulate mixed lymphocyte cultures and mitogenic responses independently of the major histocompatibility complex. Scand J Immunol 2003, 57:11-20.

46. Melief SM, Zwaginga JJ, Fibbe WE, Roelofs H: Adipose tissue-derived multipotent stromal cells have a higher immunomodulatory capacity than their bone marrow-derived counterparts. Stem Cells Transl Med 2013, 2:455-463.

47. Beyth S, Borovsky Z, Mevorach D, Liebergall M, Gazit Z, Aslan H, Galun E, Rachmilewitz J: Human mesenchymal stem cells alter antigen-presenting cell maturation and induce T-cell unresponsiveness. Blood 2005, 105:2214-2219. 
48. Zappia E, Casazza S, Pedemonte E, Benvenuto F, Bonanni I, Gerdoni E, Giunti D, Ceravolo A, Cazzanti F, Frassoni F, Mancardi G, Uccelli A: Mesenchymal stem cells ameliorate experimental autoimmune encephalomyelitis inducing T-cell anergy. Blood 2005, 106:1755-1761.

49. Li P, Li SH, Wu J, Zang WF, Dhingra S, Sun L, Weisel RD, Li RK: Interleukin-6 downregulation with mesenchymal stem cell differentiation results in loss of immunoprivilege. J Cell Mol Med 2013, 17:1136-1145.

50. Croitoru-Lamoury J, Lamoury FM, Zaunders JJ, Veas LA, Brew BJ: Human mesenchymal stem cells constitutively express chemokines and chemokine receptors that can be upregulated by cytokines, IFN-beta, and Copaxone. J Interferon Cytokine Res 2007, 27:53-64.

51. Ackermann PW, Domeij-Arverud E, Leclerc P, Amoudrouz P, Nader GA: Anti-inflammatory cytokine profile in early human tendon repair. Knee Surg Sports Traumatol Arthrosc 2013, 21:1801-1806.

52. Hosaka Y, Kirisawa R, Yamamoto E, Ueda H, Iwai H, Takehana K: Localization of cytokines in tendinocytes of the superficial digital flexor tendon in the horse. J Vet Med Sci 2002, 64:945-947.

53. Le Blanc K, Tammik C, Rosendahl K, Zetterberg E, Ringdén O: HLA expression and immunologic properties of differentiated and undifferentiated mesenchymal stem cells. Exp Hematol 2003, 31:890-896.

54. Deuse T, Stubbendorff M, Tang-Quan K, Phillips N, Kay MA, Eiermann T, Phan TT, Volk HD, Reichenspurner H, Robbins RC, Schrepfer S: Immunogenicity and immunomodulatory properties of umbilical cord lining mesenchymal stem cells. Cell Transplant 2011, 20:655-667.

55. Beggs K, Lyubimov A, Borneman JN, Bartholomew A, Moseley A, Dodds R, Archambault MP, Smith AK, Mclntosh KR: Immunologic consequences of multiple, high-dose administration of allogeneic mesenchymal stem cells to baboons. Cell Transplant 2006, 15:711-721.

doi:10.1186/scrt479

Cite this article as: Paterson et al:: Equine mesenchymal stromal cells and embryo-derived stem cells are immune privileged in vitro. Stem Cell Research \& Therapy 2014 5:90

\section{Submit your next manuscript to BioMed Central and take full advantage of:}

- Convenient online submission

- Thorough peer review

- No space constraints or color figure charges

- Immediate publication on acceptance

- Inclusion in PubMed, CAS, Scopus and Google Scholar

- Research which is freely available for redistribution 